\title{
A GLACIAÇÃO NEOPALEOZÓICA NA PORÇÃO MERIDIONAL DA BACIA SANFRANCISCANA
}

\author{
JOSÉ E.G. CAMPOS* \& MARCEL A. DARDENNE*
} \begin{abstract}
THE NEOPALEOZOIC GLACIATION IN THE SOUTHERN PORTION OF
SANFRANCISCANA BASIN. This text represents a stratigraphic and environmental study of two areas in the northwest of Minas Gerais State, Brazil. The work allowed the identification of the Permo-Carboniferous glaciation in the Sanfranciscana Basin, not yet described. A stratigraphic subdivision is proposed for the glaciogenic strata - The Santa Fé Group - which is composed of the Floresta and Tabuleiro Formations. The Floresta Formation is the basal unit and is composed of three members: Brocotó Member (tillites and tilloides), Brejo do Arroz Member (red mudstones and siltstones with a variety of dropstones) and Lavado Member (red sandstones). The Tabuleiro Formation (homogeneous sandstones) overlies all members of Floresta Formation. The arkoses of the Três Marias Formation (Upper Proterozoic) are the regional basement for the glaciogenic sequence. The Santa Fé Group is a proglacial system with tillite and tilloide facies (Brocotó Member), fluvioglacial facies (Lavado Member), glacio-lacustrine and turbiditic facies (Brejo do Arroz Member) and periglacial eolian facies (Tabuleiro Formation). The glacial sedimentation was controlled by the advance and retreat of the ice sheet. Diagenetic reactions are not well developed because of the incipient burial history. The major diagenetic feature was a calcitic pervasive cementation. The provenance areas for the glaciogenic deposits are interpreted from heavy mineral analysis, striated pavement orientation and dropstone composition. The northern Espinhaço region is proposed as the source area.
\end{abstract}

Keywords: Neopaleozoic glaciation, Sanfranciscana Basin, Minas Gerais State.

\begin{abstract}
RESUMO Este artigo representa um trabalho estratigráfico e ambiental em duas áreas do noroeste do Estado de Minas Gerais (Canabrava e Santa Fé de Minas). O trabalho possibilitou a identificação da até então desconhecida Glaciação Permo-Carbonífera na Bacia Sanfranciscana. Uma subdivisão é proposta para os estratos glaciais - Grupo Santa Fé - o qual é composto pelas Formações Floresta e Tabuleiro. A Formação Floresta é basal e constituída por três membros: Brocotó (tilitos e tilóides), Brejo do Arroz (siltitos e folhelhos vermelhos com grande variedade de seixos pingados) e Lavado (arenitos vermelhos). A Formação Tabuleiro (arenitos homogêneos) sobrepõe todos os membros da Formação Floresta. Os arcóseos e siltitos da Formação Três Marias do Proterozóico Superior representam o embasamento regional da glaciação. O Grupo Santa Fé é um sistema proglacial com fácies de tilito e tilóide (Membro Brocotó), fácies flúvio-glacial (Membro Lavado), fácies gláciolacustre e turbidítica (Membro Brejo do Arroz) e fácies periglacial eólica (Formacão Tabuleiro). A sedimentacão glacial foi controlada por avanços e recuos da capa de gelo. As reações diagenéticas não são bem desenvolvidas, por causa da incipiente história de soterramento da bacia. A principal feição diagenética foi a cimentação carbonática penetrativa. As áreas de proveniência para os depósitos glaciais são interpretadas a partir da análise dos minerais pesados, pavimentos estriados e composição dos clastos caídos. A região do Espinhaço Setentrional é proposta como área fonte.
\end{abstract}

Palavras-chave: Glaciação neopaleozóica, Bacia Sanfranciscana, Estado de Minas Gerais.

INTRODUÇÃO Este trabalho versa a respeito das coberturas sedimentares fanerozóicas do Estado de Minas Gerais, inclú́das na porção meridional da Bacia Sanfranciscana. As áreas estudadas estão situadas nas proximidades de Canabrava (distrito de João Pinheiro), Santa Fé de Minas e no Vale do Rio Urucuia. O acesso é facilitado pela BR - 040, a partir de João Pinheiro, tornando-se as rodovias estaduais que rumam para nordeste, ou a partir de Pirapora tomandose o rumo noroeste (Fig. 1). Os principais objetivos deste artigo são o estabelecimento da estratigrafia e a caracterização dos sistemas deposicionais associados à Glaciação Permo-Carbonífera na Bacia Sanfranciscana, além do seu posicionamento no contexto regional.

CONTEXTO GEOLÓGICO REGIONAL Na região abrangendo a confluência dos vales dos Rios São Francisco e Paracatu, as litologias presentes são atribuídas ao Grupo Bambuí (Proterozóico Superior), ao Grupo Santa Fé (Neopaleozóico), Formação Areado (Cretáceo Inferior) e Formação Urucuia (Cretáceo Superior).

PROTEROZÓICO Grupo Bambui O Grupo Bambuí, objeto de estudos por vários autores, entre eles Rimann (1917), Costa \& Branco (1961), Braun (1968), Scholl (1973),
Dardenne (1978) e Dardenne \& Walde (1979), é representado por um conglomerado basal (Tilito Basal), continuando com uma seqüềncia pelito-carbonatada e terminando com arcóseos e siltitos.

Atualmente, o Grupo Bambuí é caracterizado por seis formações (Dardenne 1978), da base para o topo: Jequitaí, Sete Lagoas, Serra de Santa Helena, Lagoa do Jacaré, Serra da Saudade e Três Marias.

A idade da sedimentação do Grupo Bambuí situa-se, a partir da presença de estromatólitos colunares, gêneros Gymnosolenides e Linnela Avis (Marchese 1974, Dardenne 1979), em um intervalo de 900 a $600 \mathrm{Ma}$. As datações radiométricas ( $\mathrm{Rb}$-Sr e $\mathrm{K}-\mathrm{Ar}$ ) dos eventos diagenéticos tardios, obtidas na Bahia em rochas da Formação Bebedouro, equivalente da Formação Jequitaí, resultaram em idades de cerca de 900 - 930 Ma (Macedo \& Bonhomme 1984). Outras datações radiométricas utilizando os métodos K-Ar e Rb-Sr forneceram idades entre 650 e $600 \mathrm{Ma}$ (Amaral \& Kawashita 1967, Almeida \& Hasui 1969 e Hasui \& Almeida 1970), as quais são geralmente relacionadas ao dobramento da Faixa Brasília.

PALEOZÓICO Grupo Santa Fé A primeira referência ao "Tilito Santa Fé" é atribuída a Gonzaga \& 


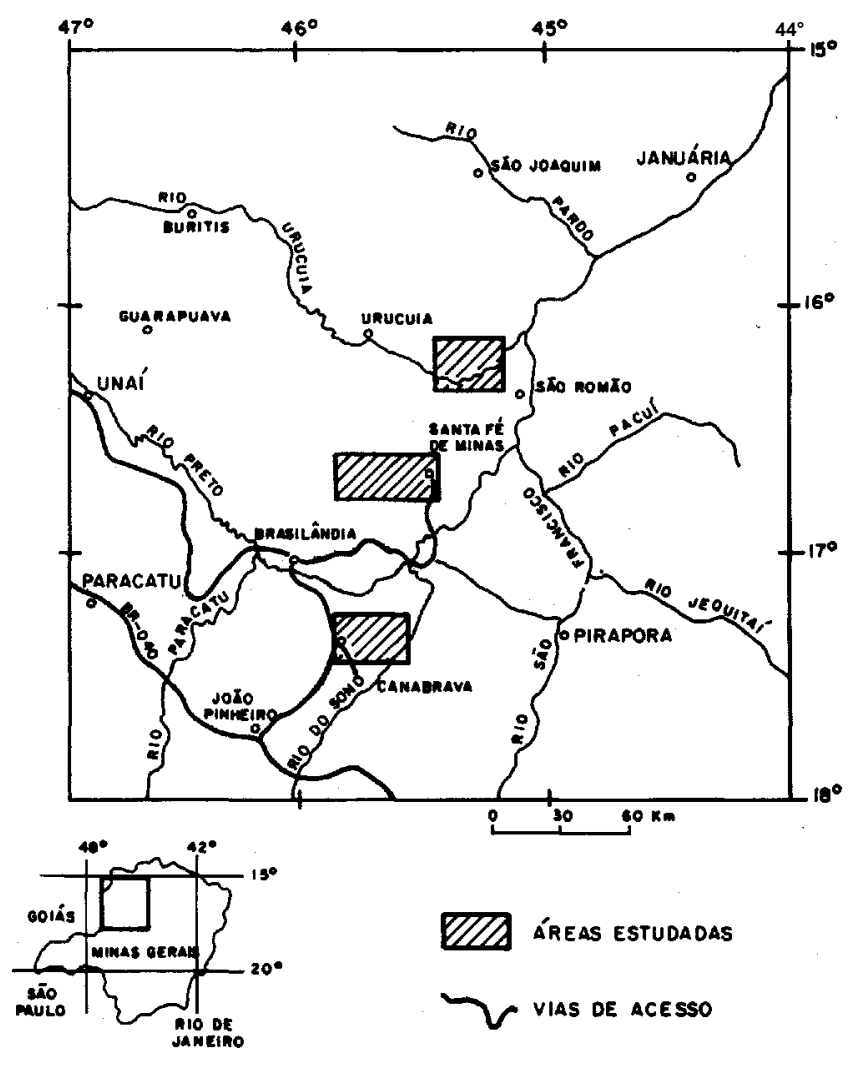

Figura l-Mapa de localização

Figure 1 - Location Map

Tompkins (1987) e Tompkins \& Gonzaga (1989), que descrevem a ocorrência de paraconglomerados contendo seixos e calhaus, na região de Canabrava e Santa Fé de Minas MG. Dardenne et al (1990), a partir da observação de pavimentes estriados próximo a Santa Fé de Minas, confirmaram a existência da glaciação e a denominação de tilitos para alguns diamictitos.

A "Seqüência Santa Fé" representa todo um conjunto com características glaciogênicas. Ocorrem todos os parâmetros necessários para a definição desse ambiente, como: pavimentes estriados com crescentic gouge, crescentic marks, clastos estriados e facetados, clastos caídos (dropstones), varvitos, seixos de rochas variadas (gnaisses, quartzitos, xistos, metaconglomerados, itabiritos, arcóseos, calcários, granites, metassiltitos, entre outros). Nos diamictitos, os clastos predominantes são os de arcóseos (cerca de $90 \%$ dos clastos), enquanto a grande diversidade composicional dos clastos é observada como dropstones nos folhelhos (Campos 1992).

CRETÁCEO INFERIOR Formação Areado A nomenclatura litoestratigráfica mais utilizada é a designação de Formação Areado, composta por três membros: Abaeté, Quiricó e Três Barras (Barbosa 1965).

Membro Abaeté - constituído por conglomerados e conglomerados arenosos contendo ventifactos. Sua espessura varia desde alguns centímetros até oito metros. O conglomerado, apesar de não ser contínuo, mostra distribuição horizontal regional. O sistema deposicional para o membro é considerado por vários autores como canais fluviais com retrabalhamento eólico esporádico.

Membro Quiricó - composto por folhelhos, siltitos e intercalações de arenitos finos. A espessura máxima alcança $100 \mathrm{~m}$. As estruturas comumente encontradas são as estratificações plano-paralelas e cruzadas e, com menor freqüência, marcas onduladas e marcas de cubos de sal (Moraes et al. 1986). A sedimentação Quiricó é atribuída a um ambiente lacustre com contribuição de correntes de turbidez (Moraes et al. 1986 e Sgarbi 1989). Kattah (1991) assinala a contribuição de ambiente marinho, a partir da presença de possíveis radiolários.

Membro Três Barras - é constituído por arenitos médios vermelhos ou rosados onde as estratificações cruzadas de grande porte e as estratificações plano-paralelas são as estruturas mais comuns. A espessura máxima foi encontrada no ribeirão homônimo e é da ordem de $140 \mathrm{~m}$. Seu ambiente de deposição é controvertido, sendo que os autores sugerem sistemas variados para as respectivas áreas estudadas: deposição eólica, fluvial com depósitos de canais e de planície de inundação e flúvio-deltáica.

CRETÁCEO SUPERIOR Formação Urucuia A Formação Urucuia recobre a Formação Areado em discordância paralela. No contexto regional, é composta essencialmente por arenitos maduros, finos a médios, brancos, róseos ou avermelhados. Níveis conglomeráticos são sempre citados nos mapeamentos, sendo encontrados em várias posições estratigráficas dentro da formação e interpretados como depósitos de wadis.

Os ambientes deposicionais associados à sedimentação de toda a Formação Urucuia são considerados como associados a um sistema desértico com fácies fluviais, lacustres e eólicas. As estruturas sedimentares, como as megaestratificações cruzadas e as estratificações plano-paralelas, auxiliam na determinação dos sistemas sedimentares. Oliveira (1967) considerou uma passagem lateral de ambientes eólicos e fluviais.

Apesar da ausência de fósseis, a Formação Urucuia é considerada como de idade cretácea superior, pois se interdigita com as lavas e tufos da Formação Mata da Corda com datação de 80 Ma pelo método K-Ar.

ESTRATIGRAFIA E PETROGRAFIA Foram identificadas a Formação Três Marias, do Grupo Bambuí, atribuída ao fim do Proterozóico; o Grupo Santa Fé, pertencente ao Neopaleozóico; e os conglomerados e arenitos correlacionados ao Cretáceo Inferior, que são agrupados na Formação Areado. As figuras 2 e 3 apresentam os mapas geológicos das áreas estudadas.

FORMAÇÃO TRÊS MARIAS - PROTEROZÓICO SUPERIOR O embasamento regional das coberturas fanerozóicas no extremo noroeste mineiro é constituído essencialmente pela Formação Três Marias do Grupo Bambuí. Muito localmente, em áreas movimentadas por falhas, ocorrem ainda as formações do Subgrupo Paraopeba sensu latu no sentido de Braun (1968) (Formação Sete Lagoas e/ou possivelmente outras).

A Formação Três Marias é constituída por siltitos micáceos, siltitos argilosos e arcóseos com granulometria variada. Os arcóseos ocorrem como bancos centimétricos a métricos interacamadados com as litologias mais finas. Os litotipos Três Marias apresentam cores verdes ou vermelhas e, nas áreas estudadas, são predominantemente vermelhos e, às vezes, com tons amarronzados. Os arcóseos são sempre muito duros em virtude da alta compactação, e apresentam esfoliação esferoidal.

O estudo das seções delgadas mostrou grãos de quartzo extremamente angulosos, quantidades de feldspatos sempre superiores a $25 \%$, chegando a até $40 \%$ em algumas amostras. A presença de micas brancas orientadas segundo o acamamento, muitas vezes deformadas pela compactação, é constante. A associação de minerais pesados é constituída por óxidos de ferro, que localmente marcam o acamamento (até 3\%), além de turmalina, zircão, epídoto e granadas. 

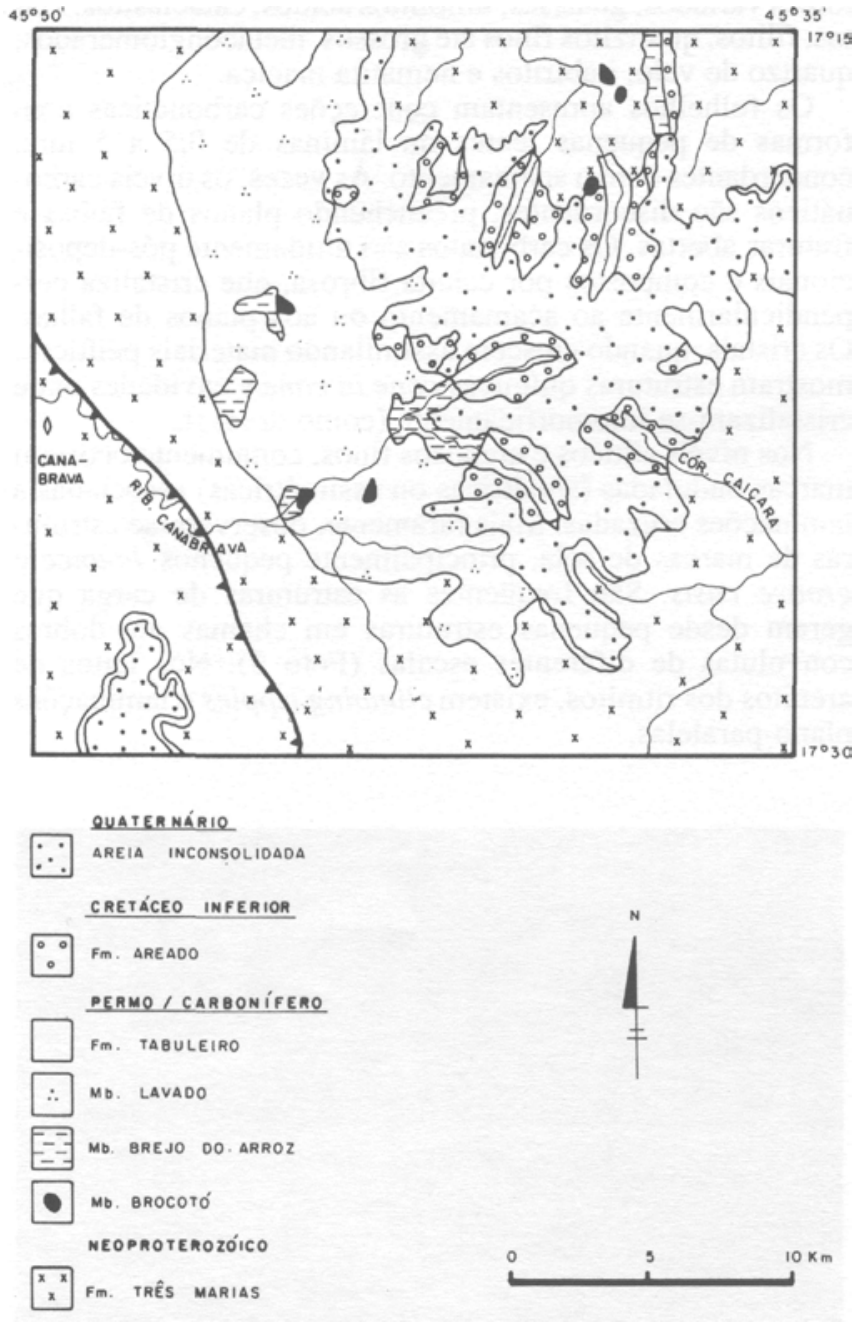

Figura 2 - Mapa geológico da área de Canabrava Figure 2 - Geologic map of the Canabrava area

Os litotipos Três Marias, sobretudo os arcóseos, mostram várias estruturas sedimentares, tanto sin quanto pós-deposicionais. As marcas onduladas são muito comuns e variáveis (simétricas ou assimétricas, com maiores ou menores comprimentos de ondas e amplitudes), inclusive indicando paleocorrentes opostas. As estruturas em chama e pseudonódulos ocorrem quando bancos de arcóseos sobrepõem material mais argiloso. Ainda ocorrem estratificações sigmoidais e grandes estruturas tipo hummocky.

As estruturas sedimentares e a vasta distribuição horizontal permitem enquadrar a deposição da Formação Três Marias em um ambiente de plataforma marinha.

GRUPO SANTA FÉ - NEOPALEOZÓICO O Grupo Santa Fé é composto pelas Formações Floresta e Tabuleiro. A Formação Floresta, por sua vez, é constituída por três membros: Brocotó, Brejo do Arroz e Lavado, os quais relacionam-se por contatos laterais interdigitados. A Formação Tabuleiro se individualiza recobrindo os membros da Formação Floresta e inclusive ocorrendo diretamente sobre a Formação Três Marias.

As unidades citadas anteriomente são encontradas e definidas nas áreas de Santa Fé de Minas e Canabrava e a sua nomenclatura estratigráfica tem base em feições geográficas e geomorfológicas da região.

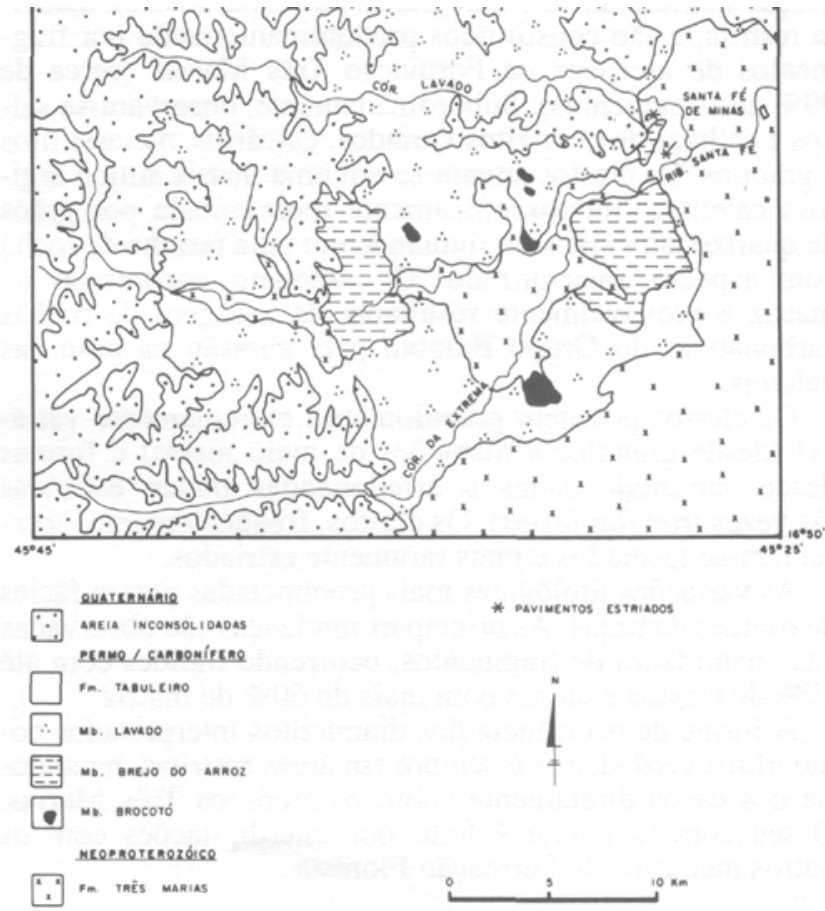

Figura 3 - Mapa geológico da área de Santa Fé de Minas Figure 3 - Geologic map of the Santa Fé de Minas area

FORMAÇ̃̃O FLORESTA Os três membros foram englobados em apenas uma formação, pois mostram contatos laterais e verticais interdigitados.

Membro Brocotó O Membro Brocotó é constituído essencialmente por tilitos e tilóides, com coloração vermeIha-tijolo (Foto 1). Foram considerados como tilitos verdadeiros aqueles diamictitos não-estratificados, maciços, com blocos e calhaus angulosos e/ou estriados, enquanto os estratificados, com clastos mais arredondados foram classificados nas fácies de tilóides. Contudo, os dois grupos são incluídos no Membro Brocotó, já que seu transporte e deposição são ligados diretamente à presença de capas de gelo.

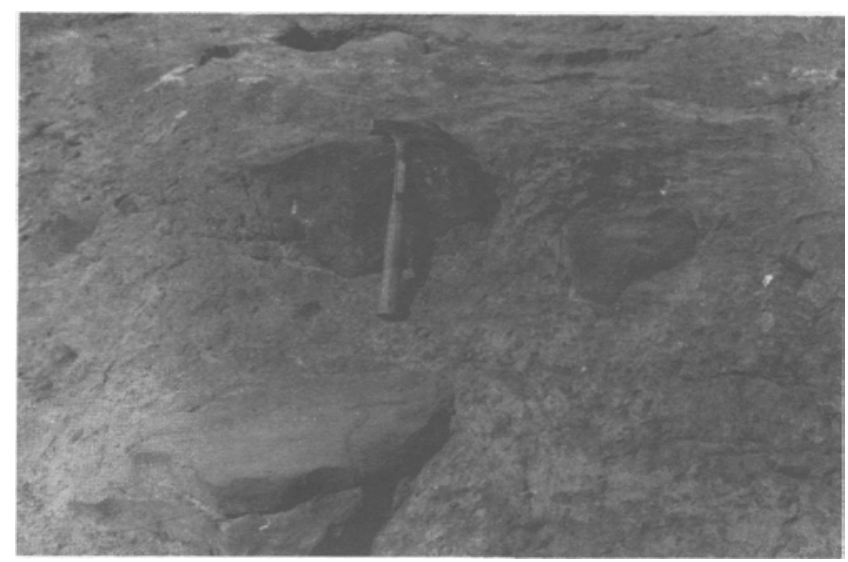

Foto 1 - Fácies de tilitos apresentando seixos e calhaus angulosos flutuantes em matriz síltico-argilosa

Photo 1 - Tillite fácies showing pebble and boulders in a fine grained matrix 
Estes diamictitos são encontrados em vasta região da porção meridional da Bacia Sanfranciscana, mas de maneira restrita, e são constituídos predominantemente por fragmentos de arcóseos da Formação Três Marias (cerca de $90 \%$ dos fragmentos). Subordinadamente, observam-se seixos e calhaus de quartzitos variados, calcários, metassiltitos e granites. Os clastos situam-se em uma matriz síltico argilosa calcífera, microscopicamente representada por grãos de quartzo tamanho silte flutuando em uma farinha de rocha com aspecto amarronzado. $\mathrm{O}$ carbonato encontrado na matriz é provavelmente resultante da moagem de rochas carbonáticas do Grupo Bambuí pela abrasão na base das geleiras.

Os clastos possuem granulometria extremamente variável (desde granules a matacões de meio metro) e formas desde subarredondadas a arredondadas pouco esféricas (às vezes iron flat forms\}. Os clastos, freqüentemente, apresentam-se facetados e mais raramente estriados.

As variações litológicas mais pronunciadas geram fácies de tilóides distintas. As principais mudanças são observadas nas quantidades de fragmentos, ocorrendo tilóides com até $70 \%$ de clastos e outros com mais de $60 \%$ de matriz.

A forma de ocorrência dos diamictitos interpretados como tilitos verdadeiros é sempre em áreas restritas, na maioria dos casos diretamente sobre os arcóseos Três Marias. O seu contato lateral é feito por interdigitações com os outros membros da Formação Floresta.

Membro Brejo do Arroz O Membro Brejo do Arroz é definido basicamente por folhelhos vermelhos (muito raramente esverdeados quando lixiviados), bem laminados, com ou sem clastos caídos que perturbem a laminação primária (Foto 2). São comuns as intercalações de níveis centimétricos de arenitos finos rosados e ritmitos com aspecto várvico. Ocorrem ainda siltitos, arenitos e conglomerados vermelhos intercalados como níveis decimétricos a métricos, apresentando contatos bruscos com os folhelhos.

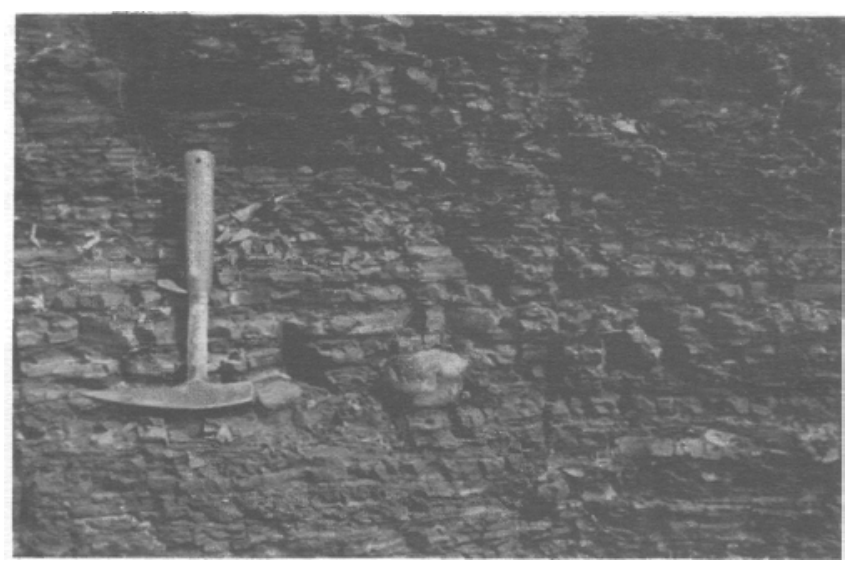

Foto 2 - Folhelhos e siltitos do Membro Brejo do Arroz com clastos caídos de quartzitos

Photo 2 - Brejo do Arroz Member siltstones and mudstones with quanzite dropstones

Os materiais caídos nos folhelhos apresentam formas irregulares, mais freqüentemente angulosos, mas sempre com uma face achatada, às vezes estriada; comumente se observam direções oblíquas de estrias no mesmo clasto. São extremamente mal selecionados, com diâmetros variando de milímetros a decímetros e, excepcionalmente, atingindo $3 \mathrm{~m}$. Estes fragmentos também são caracterizados por grande variabilidade composicional, apresentando diversos tipos petrográficos: arcóseos, meiassiltitos, calcários, granitóides variados, gnaisses, milonitos ácidos, cataclasitos, xistos, filitos, quartzitos finos até grossos, metaconglomerados, quartzo de veio, itabiritos e hematita maciça.

Os folhelhos apresentam concreções carbonáticas com formas de pequenas lentes ou lâminas de 0,5 a $5 \mathrm{~mm}$, concordantes com o acamamento. As vezes, os níveis carbonáticos são discordantes, preenchendo planos de falhas e fraturas abertas. Os carbonates são nitidamente pós-deposicionais e compostos por calcita fibrosa, que cristaliza perpendicularmente ao acamamento ou aos planos de falhas. Os cristais, quando crescem assimilando materiais pelíticos, mostram estruturas químicas cone in cone e cavidades onde cristalizam-se idiomorficamente (como drusas).

Nos níveis sílticos e arenosos finos, comumente ocorrem marcas onduladas (simétricas ou assimétricas) associadas a laminações cruzadas. Mais raramente, observam-se estruturas de marcas de sola, principalmente pequenos bounce e groove casts. São freqüentes as estruturas de carga que geram desde pequenas estruturas em chamas até dobras convolutas de diferentes escalas (Foto 3). Nos leitos de arenitos dos ritmitos, existem climbing ripples e laminações plano-paralelas.

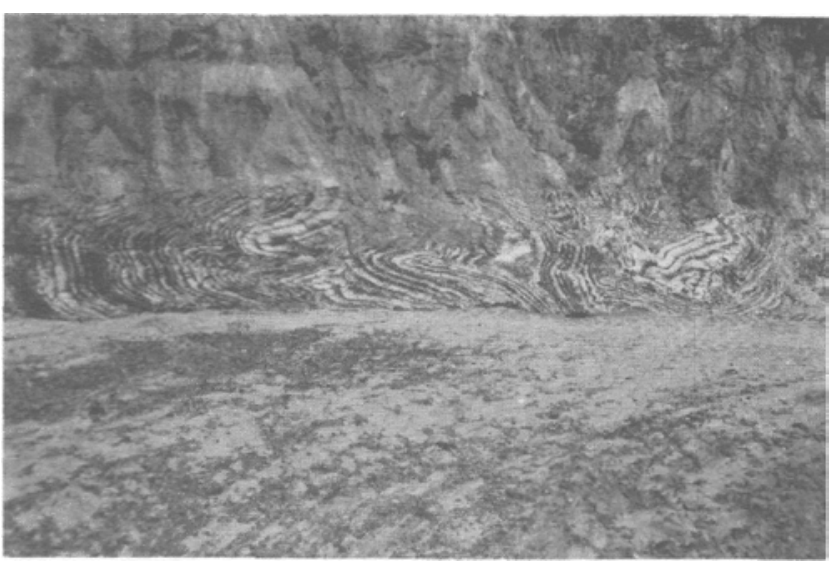

Foto 3 - Folhelhos glácio-lacustres apresentando estrutura de fluidização

Photo 3 - Glacio-lacustrine mudstones showing disharmonic folds (fluid scape structure)

O Membro Brejo do Arroz interdigita-se com os Membros Brocotó e Lavado. Geralmente, sobrepõe-se diretamente aos arcóseos da Formação Três Marias.

Membro Lavado É constituído por arenitos vermelhos bastante heterogêneos. Secundariamente, ocorrem diamictitos com matriz arenosa, conglomerados finos e conglomerados intraformacionais.

Os arenitos variam desde muito finos a médios, argilosos ou não, sempre com cimento calcífero quando frescos. Ocorrem porções com cimento sintaxial ou poiquilotópico, gerando cristais de 1 a $4 \mathrm{~cm}$ de calcita.

Microscopicamente, são classificados (segundo Folk 1956) como quartzo arenitos, arenitos feldspáticos e arcóseos. Na composição elástica, o quartzo é sempre o mineral predominante, com grãos exibindo extinção desde normal a fortemente ondulante. Os feldspatos mostram variação modal de $\mathrm{O}$ a $30 \%$, sendo representados por plagioclásio e microclínio, em proporções iguais e raramente alterados. Ainda ocorrem muscovitas em concentrações máximas de $2 \%$ e orientadas segundo o acamamento. Os minerais pesados constituem geralmente $1 \%$ do total e são representados por turmalinas, 
zircão, epídoto, zoizita, granadas, magnetita, ilmenita e hematita. Algumas fácies ricas em óxidos (magnetita, hematita $\mathrm{e}$ ilmenita) mostram teores da ordem de 5\%.

Existem variedades texturalmente maduras e imaturas, ocorrendo ainda associações de clastos arredondados e esféricos com grãos angulosos.

A porosidade primária é alta; contudo, a cimentação penetrativa tende a obliterá-la, gerando porosidade residual baixa. Os grãos detríticos sempre apresentam em sua superfície um filme de óxidos, que é responsável pela coloração vermelha dos arenitos.

As estruturas sedimentares comuns são as laminações cruzadas acanaladas, estratificações cruzadas e plano-paralelas, dobras convolutas em várias escalas (Foto 4) e feições de corte e preenchimento.

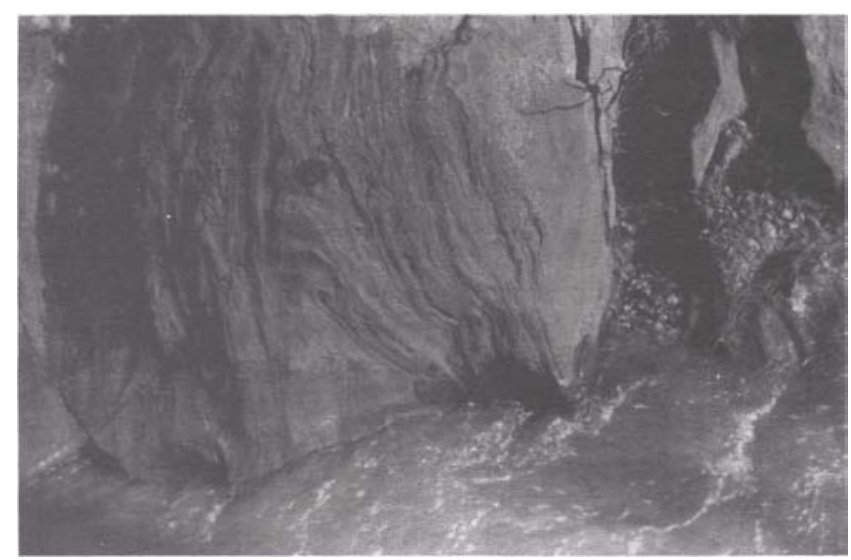

Foto 4 - Estrutura de fluidização em arenito do Membro Lavado

Photo 4 - Lavado Member sandstones with fluidization structure

Formação Tabuleiro A formação é constituída por arenitos homogêneos, vermelhos, rosados e, localmente, brancos com delgadas intercalações argilosas. São expostos em bancos horizontais, sendo a estratificação plano-paralela a estrutura mais importante (bancos de 0,5 a $2 \mathrm{~m}$ ). As estratificações cruzadas pequenas e médias são muito locais.

A análise das lâminas delgadas mostra grãos de quartzo muito arredondados e esféricos, em torno de $0,25 \mathrm{~mm}$ de diâmetro (há raros níveis bimodais), contatos pontuais e uma película de óxidos em volta dos grãos. Os grãos detríticos de óxidos, bem esféricos, raramente atingem $2 \%$. A porosidade inicial elevada (até $15 \%$ ) é totalmente preenchida por calcita bem cristalizada. $\mathrm{O}$ arenito mostra alta maturidade textural e mineralógica, excelente selecionamento, sendo classificado como quartzo arenito médio calcífero.

Alguns níveis mostram clastos de argilitos vermelhos, geralmente mais grossos que os grãos de quartzo e provavelmente oriundos da Formação Floresta.

A Formação Tabuleiro recobre todas as unidades descritas anteriormente, inclusive a Formação Três Marias, indicando distribuição mais ampla. A passagem dos membros da Formação Floresta para a Formação Tabuleiro é gradacional e caracterizada pela intercalação de folhelhos do Membro Brejo do Arroz nos arenitos.

Para norte, na região do Vale do Rio Urucuia, esta unidade se torna mais importante, com espessuras superiores a 50 $\mathrm{m}$ e grande continuidade lateral.

MEMBRO ABAETÉ-CRETÁCEO INFERIOR Este membro é apenas bem preservado nas proximidades de Canabrava, com $5 \mathrm{~m}$ de espessura média, mas atingindo localmente $30 \mathrm{~m}$ (Campos et al. 1992). Em Santa Fé de Minas, foi intensamente retrabalhado, restando apenas raros testemunhos.

A sucessão de conglomerados que predomina nesta unidade é grossa, com seixos de quartzitos variados, quartzo e raros arcóseos, itabiritos, granitos e arenitos. E comum a presença de seixos facetados, interpretados como ventifactos verdadeiros. A granulometria varia desde seixos com $2 \mathrm{~cm}$ até calhaus com $40 \mathrm{~cm}$, predominando os clastos de $7-8 \mathrm{~cm}$ de diâmetro. A matriz geralmente inferior a $20 \%$ é constituída por areia grossa e alguma argila. Os conglomerados se associam lateral e verticalmente (interdigitação e recobrimento) com arenitos médios vermelhos.

Os arenitos são impuros e cimentados por silica, óxidos e hidróxidos de ferro, além de conter grãos de silexitos (até $20 \%$ ), plagioclásio (até $2 \%$ ), óxidos detríticos $(3-4 \%)$ e raros pesados (zircão e turmalina).

As estruturas deposicionais comumente observadas são o imbricamento de seixos, acamamento gradacional, canais de corte e preenchimento, além de estratificações cruzadas acanaladas.

A associação litofaciológica descrita permite correlação segura com o Membro Abaeté da Formação Areado (Campos et al. 1992). Ocorre recobrindo o Grupo Santa Fé ou diretamente sobre o Grupo Bambuí, por discordância erosiva.

O ambiente gerador desta unidade é interpretado como um sistema fluvial entrelaçado com retrabalhamento eólico. Os ventifactos indicam que, após a deposição em fluxo aquoso, os seixos (pelo menos os mais superficiais) foram expostos a um regime desértico.

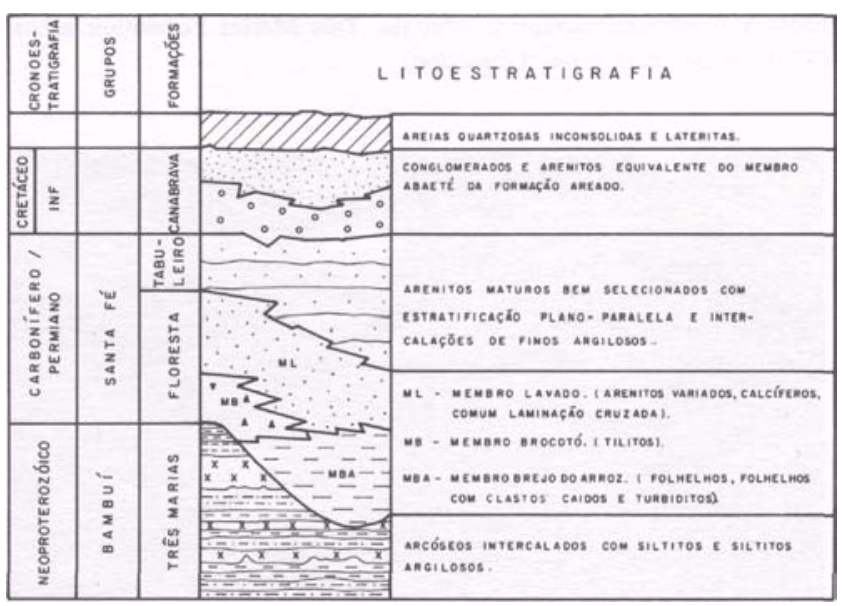

Figura 4 - Estratigrafia integrada, regiões de Santa Fé de Minas e Canabrava

Figure 4 - Stratigraphy of Santa Fé de Minas and Canabrava regions

GEOLOGIA DO GRUPO SANTA FÉ - SISTEMAS DEPOSICIONAIS O arcabouço deposicional de todo o Grupo Santa Fé é representado por um sistema glacial com várias associações de fácies pró e peri-glaciais (Edwards 1987). Pode-se identificar litofácies depositadas por bases de geleiras (fácies de tilito), processos fluviais (fácies flúvioglacial), processos lacustres (fácies glácio-lacustre), processos gravitacionais (fácies de turbidito) e processos eólicos (fácies eólico periglacial).

As principais feições descritas são discutidas por Harland et al (1966), Boulton (1972), Dreimanis \& Schuluchter (1985), França (1987) e Eyles \& Eyles (1992); contudo, a maior parte da bibliografia disponível trata de sistemas glaciais costeiros, com associações glácio-marinhas cujos modelos não são aplicáveis à Glaciação Santa Fé. 
Utilizando os critérios (seqüência de fácies, abundância e geometria dos corpos de arenitos associados a diamictitos e as características dos tilitos) propostos por Miller (1989) para a análise dos ciclos de avanços e recuos de geleiras durante um período glacial, pode-se concluir que todo o pacote glaciogênico processou-se por avanços e recuos da capa de gelo.

Os principais argumentos que, somados, evidenciam e comprovam a existência da glaciação, estão resumidamente enumerados a seguir:

- Presença de pavimentes estriados e ondulados com crescentic fractures e crescentic marks (Foto 5 e 6);

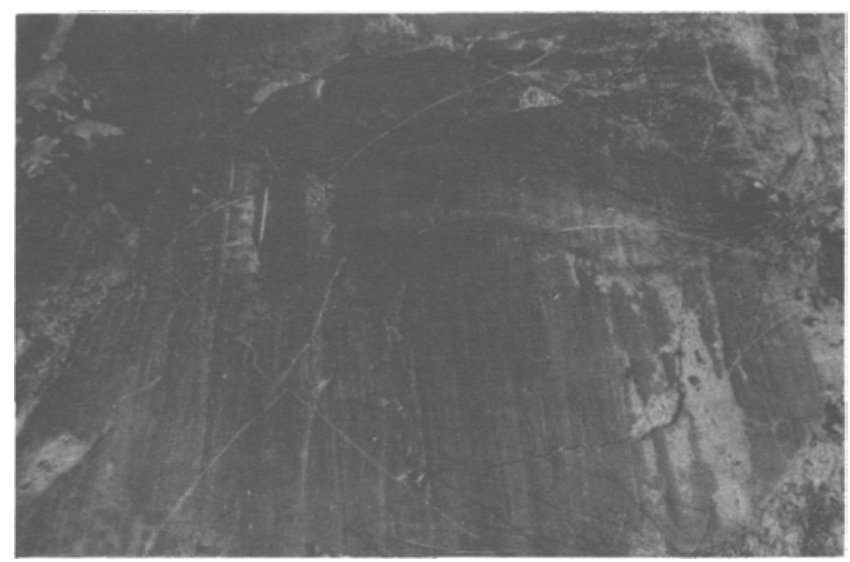

Foto 5 - Pavimento polido e estriado sobre os arcóseos da Formação Três Marias (direção geral das estrias S20W) Photo 5 - Striated pavement over the Três Marias Formation arkoses ( $\mathrm{S} 20 \mathrm{~W}$ is the striae general direction)

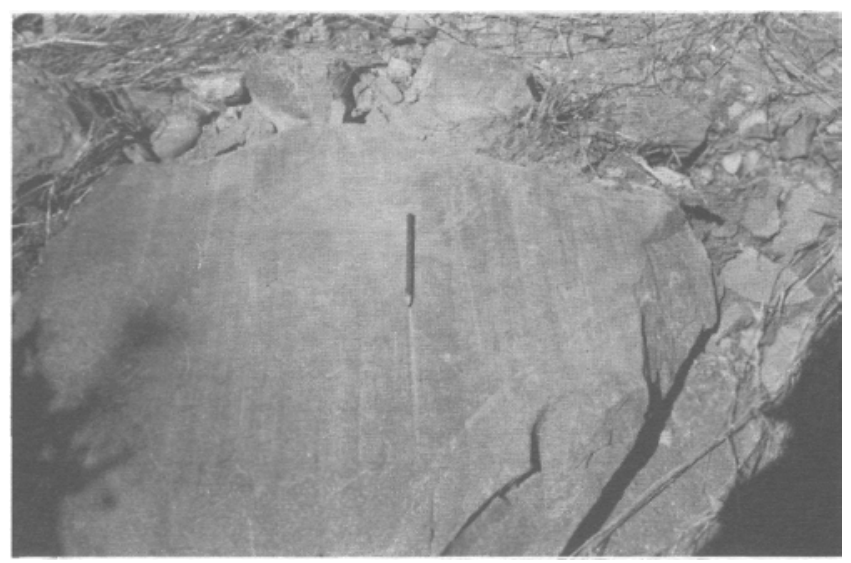

Foto 6 - Bloco de pavimento estriado indicando a passagem sucessiva de geleiras

Photo 6 - Striated pavement boulder showing sucessive ice sheet movement

- Clastos caídos, às vezes estriados, com grande variabilidade de forma, tamanho e composição;

- Caráter não-estratificado da maioria dos diamictitos, além da natureza síltico-argilosa calcífera da matriz;

- Associações de litofácies periglaciais típicas;

- Ocorrência dos sedimentos em vales largos em "U" (esta feição foi identificada no campo com o auxílio do altímetro a partir da determinação das cotas do contato dos sedimentos glaciogênicos com a Formação Três Marias);

- Presença comum de estruturas de deformação pós-deposicionais (dobras convolutas, leitos rompidos, estruturas em chama etc.), muito similares às descritas por Banerji
\& Sen (1991) nos sedimentos glaciais gondwânicos da índia.

Os sistemas deposicionais serão descritos a seguir, conforme a divisão estratigráfica anteriormente apresentada.

\begin{tabular}{|c|c|c|c|}
\hline \multirow{3}{*}{ 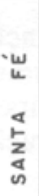 } & FORMAÇŌES & MEMBROS & $\begin{array}{l}\text { SISTEMAS } \\
\text { DEPOSICIONAIS }\end{array}$ \\
\hline & TABULEIRO & & PERIGLACIAL EÓLICO- LACUSTRE \\
\hline & \multirow{3}{*}{ FLORESTA } & LAVADO & FLUVIO - GLACIAL \\
\hline \multirow{2}{*}{$\begin{array}{l}\circ \\
\frac{0}{2} \\
\frac{\alpha}{0}\end{array}$} & & BREJO DO ARROZ & GLACIO-LACUSTRE + TURBIDÍTICO \\
\hline & & BROCOTÓ & BASE DE MORAINAS \\
\hline
\end{tabular}

Figura 5 - Relação entre a estratigrafia e os sistemas deposicionais para o Grupo Santa Fé

Figure 5 - Relationship between the stratigraphy and the depositional systems of the Santa Fé Group

Membro Brocotó - Fades de tilitos O processo de deposição deste membro está associado às bases de morainas, gerando rochas mal selecionadas depositadas como resíduos do derretimento de capas de gelo. O fato de ocorrer predomínio de fragmentos do embasamento local (arcóseos da Formação Três Marias) e de os tilitos serem restritos arealmente pode indicar que se trata de geleiras terminais que alcançaram grandes distâncias.

Este sistema deposicional é acompanhado por uma importante fase erosional, com abrasão do embasamento pelas bases das geleiras. Os vales em "U" são interpretados como a expressão em escala regional do que se observa nos pavimentos estriados do tipo ondulado.

A presença de conglomerados com estratificação incipiente indica o retrabalhamento de tilitos por correntes aquosas superimpostas. A gênese deste conglomerado pode ser explicada a partir da entrada de geleiras em paleolagos. Esta interpretação é corroborada pelos dados de campo que mostram tilitos estratificados interdigitados com folhelhos glácio-lacustres.

Depósitos ligados à circulação de fluidos intrageleiras, como os eskeres, não foram observados.

Membro Brejo do Arroz - Fácies glácio-lacustres e turbidíticas $\mathrm{O}$ Membro Brejo do Arroz representa a deposição lacustre ligada diretamente à glaciação. Os paleolagos são formados nas porções mais profundas dos próprios vales glaciais, em depressões já existentes no embasamento ou pelo represamento de rios pelos depósitos glaciais.

O preenchimento dos paleolagos se processa pela deposição de argila por gravidade. Em áreas mais restritas, a sedimentação foi controlada por variações climáticas sazonais, gerando os sedimentos com aspecto várvico.

Os dropstones (seixos, calhaus e matacões caídos) representam materiais soltos por icebergs que flutuavam nos lagos e amostravam as áreas fonte.

A chegada de geleiras carregadas de sedimentos perturba a estabilidade deposicional dos lagos e propicia a geração de correntes de turbidez. A deposição turbidítica é o resultado da entrada do sistema flúvio-lacustre nos lagos maiores. A desembocadura dos rios com correntes densas, principalmente em épocas de degelo pronunciado, acarreta a formação de pequenos canhões que espalham os detritos em forma de leques, coalescendo em profundidade. Esse sistema gera bancos com acamamento grano-decrescente (fining upwards\}, além de marcas de sola, contatos erosivos, climbing ripples e truncamento de seqüencias. Outra possibilidade para a geração das correntes de turbidez é o out- 
wash das bases de geleiras que chegavam nos paleo-lagos. Este processo deve ser responsável principalmente pelos turbiditos mais densos (Walker 1979).

Os registros sedimentares nas áreas estudadas indicam que houve lagos de diversos tamanhos e profundidades. A seqüência vertical, por outro lado, indica que os lagos são gradativamente assoreados em certas épocas, pois observam-se níveis de siltitos e arenitos finos com laminações cruzadas e marcas onduladas, denotando superfície contínua lateralmente, com lâmina de água mais rasa.

Os folhelhos do Membro Brejo do Arroz mostram, com freqüência, deformação sin-sedimentar, que resulta em dobramentos convolutos. Tais estruturas são interpretadas como formadas pelo escape de fluidos (água conata): peso dos sedimentos sobrepostos, escorregamentos ou movimentos relativos de blocos em falhas sin-sedimentares (Lowe 1975, Elliot 1965) (Foto 3).

Membro Lavado - Faties flúvio-glaciais Os depósitos encontrados no Membro Lavado são consistentes com os sistemas fluviais do tipo braided.

A grande distribuição horizontal dessa fácies indica um sistema fluvial com muitos distributaries e composto por canais migrantes lateralmente. As texturas, granulometria e estruturas dos sedimentos possibilitam enquadrá-los nas fácies Gt, Sh, Fl e Fm de Miall (1977). As feições mostram deposição em regime de fluxo inferior.

As estruturas de escape de fluidos (geralmente as dobras em cúspide localizadas), ocorrem, com freqüência, nos arenitos. Os mecanismos de geração mais prováveis seriam o peso das geleiras ou a crioturbação (deformação dos arenitos a partir do congelamento/descongelamento da água intersticial).

Os raros conglomerados que ocorrem foram interpretados como canais fluviais superimpostos, sendo muitas vezes preenchidos por clastos intraformacionais (fragmentos dos próprios arenitos).

A imaturidade mineralógica da maior parte dos arenitos encontrados em todo o membro é atribuída aos parâmetros ambientais (principalmente o clima) que diminuiram o desgaste químico dos clastos instáveis.

Formação Tabuleiro - Fácies periglacial eólicas A primeira tentativa de interpretação ambiental para os arenitos da Formação Tabuleiro, utilizando apenas os parâmetros macroscópicos, é de certa forma dificultada, pois a única estrutura sedimentar encontrada é a estratificação planoparalela (bancos decimétricos a métricos). Contudo, a análise petrográfica através das seções delgadas indica tratar-se de deposição de areias eólicas (Foto 7) em lagos rasos implantados ao final da glaciação.

Este ambiente é representado por um deserto periglacial com transporte e deposição de areia eólica em lagos pósglaciais. As areias são depositadas em lâminas d'água (lagos resultantes do relevo pós-glacial), o que explica a quase total ausência de estratificações cruzadas características de deposição por ventos.

A instalação de um ambiente eólico nas porções distais dos centros glaciais é atribuída à instabilidade climática e aos ventos causados pela convecção das massas de ar geladas (Edwards 1987).

No caso da Formação Tabuleiro, que mostra passagem vertical transicional com os membros da Formação Floresta, o deserto instalou-se após o período glacial sensu stricto. A Formação Tabuleiro não sofreu qualquer interferência direta da glaciação (retrabalhamentos por afluxo oriundo do degelo). Outro fator indicador da presença do deserto, já no fím da glaciação, é a grande dispersão horizontal da unidade (centenas de quilômetros quadrados), inclusive recobrindo regiões sem os registros glaciais.

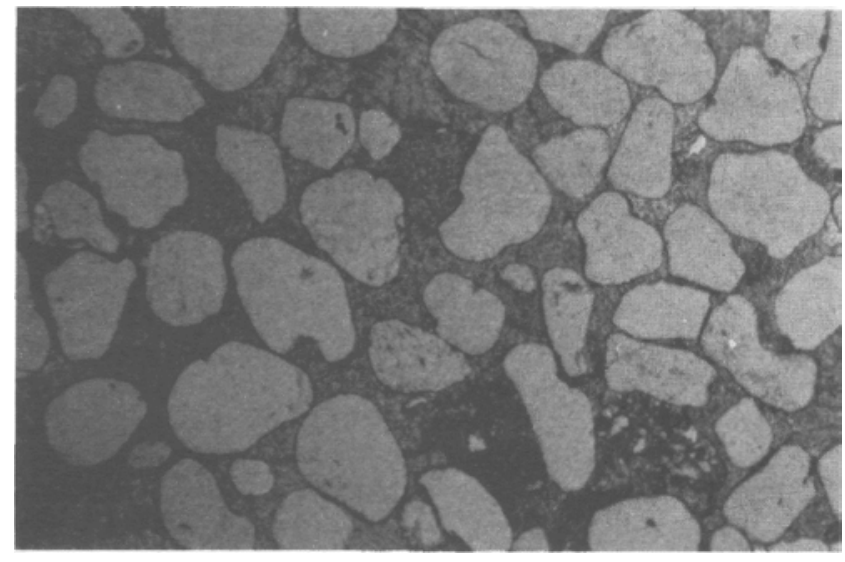

Foto 7 - Arenito da Formação Tabuleiro com grãos muito arredondados e esféricos, típicos de retrabalharnento eólico

Photo 7 - Tabuleiro Formation sandstones with very well rounded and spheric grains evidencing aeolic reworking

AREA FONTE A análise das áreas fonte, para os sedimentos glaciais depositados na Bacia Sanfranciscana, no Neopaleozóico, é facilitada por alguns aspectos que possibilitam grande precisão na determinação de sua origem.

Os principais parâmetros utilizados para a identificação da proveniência do Grupo Santa Fé foram: observação das paleocorrentes a partir dos pavimentes estriados, estudo do comportamento ótico do quartzo detrítico, estudo da associação de minerais pesados e estudo dos macroclastos que ocorrem como dropstones nas fácies glácio-lacustres.

Os vetores medidos nas áreas de ocorrência dos pavimentos estriados variam entre S10-20W e as paleocorrentes obtidas pela análise das fraturas em crescente indicam movimentação de massa de nordeste para sudoeste. Os pavimen tos estriados foram encontrados apenas em três pontos, posto que sua preservação é bastante difícil; contudo, a direção e sentido obtidos podem ser considerados como direção geral de fluxo das geleiras.

Outro fator importante para a elucidação de fontes de rochas clásticas, principalmente para os arenitos, é o estudo do comportamento ótico dos grãos de quartzo utilizando os princípios de Basu (1985). Após uma análise quali- e quantitativa dos clastos de quartzo, observou-se maior presença de grãos monocristalinos. A extinção dos grãos varia desde normal a fortemente ondulante, não havendo predominância entre os vários tipos. A interpretação desses dados leva a uma área fonte complexa com rochas plutônicas ácidas (grãos com extinção normal ou fracamente ondulante) e rochas gnáissicas (grãos com forte extinção ondulante). Os grãos policristalinos indicam veios de quartzo, chert, quartzo de rochas cataclásticas e miloníticas como fontes.

Nas variedades de rochas imaturas (arcóseos e arenitos feldspáticos), tentou-se fazer uma relação (razão) da concentração modal dos tipos de feldspatos. O resultado obtido foi um balanceamento global, não ocorrendo predominância de feldspatos potássicos (índices de fontes ácidas) ou plagioclásios (índices de fontes básicas). Dessa forma, interpretou-se uma área fonte com rochas básicas e ácidas.

A associação de minerais pesados, composta por óxidos, zircão, epídoto, zoizita, turmalina e raras granadas e apatitas, foi encontrada em todos os tipos de arenitos e na matriz dos tilitos. A paragênese dos minerais pesados também indica áreas fonte mistas com rochas básicas, ácidas e outras.

O principal parâmetro que, somado aos demais, possibilitou a proposição segura da região fonte, foi a presença dos 


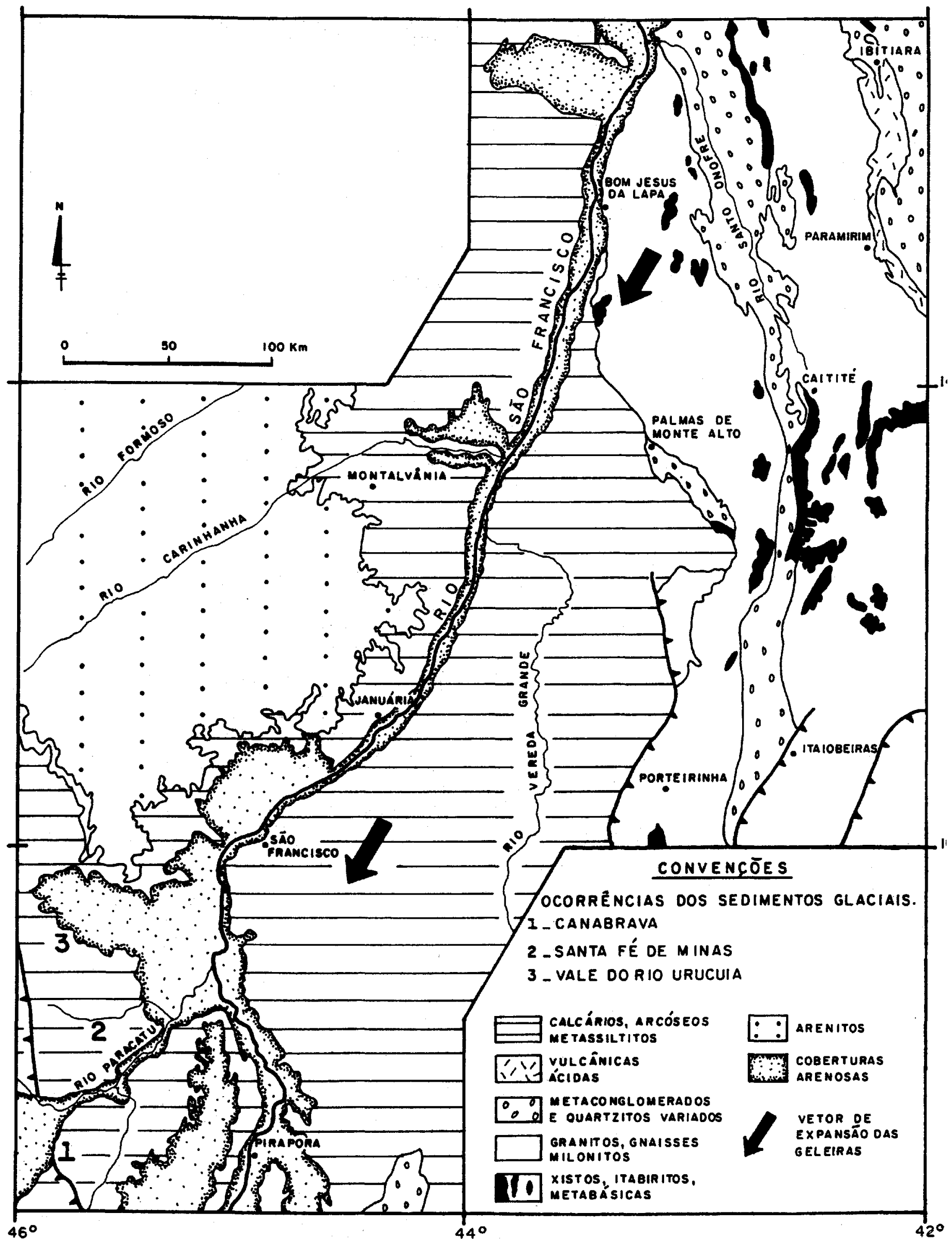

Figura 6 - Mapa de situação de áreas fontes et al. (adaptado de Schobbenhaus et al. 1984) Figure 6 - Provenance area map (after Schobbenhaus et al. 1984) 
macroclastos observados nas facies glácio-lacustres (Membro Brejo do Arroz - Formação Floresta). Os dropstones, como descritos na petrografia, são muito variáveis composicionalmente, significando que amostravam uma região geologicamente complexa.

A área fonte é, então, interpretada como a região sul do Estado da Bahia a sudoeste da Chapada Diamantina. O contexto geológico pode ser visualizado na figura 6 e é representado pelas seguintes unidades: Grupo Chapada Diamantina (Espinhaço Setentrional), com quartzitos, filitos, vulcânicas ácidas e metaconglomerados líticos (Foto 8); seqüências vulcano-sedimentares do Proterozóico Inferior, com xistos, rochas básicas, itabiritos, milonitos; faixas restritas de terrenos do tipo Greenstone Belts, com rochas básicas, xistos, rochas vulcânicas diversas e itabiritos; terrenos de embasamento gnáissico, com gnaisses, granitos intrusivos e faixas miloníticas e metaconglomerados, quartzitos e carbonatos do Grupo Macaúbas (Schobbenhaus et al. 1984).

Ocorrem, também, como clastos caídos, alguns tipos petrográficos considerados como rochas exóticas (rochas restritas a certas localidades): os filitos hematíticos (diques e sills do Grupo Espinhaço), metaconglomerados do tipo Sopa-Brumadinho, itabiritos dobrados, como os das seqüências vulcano-sedimentares, e outras.

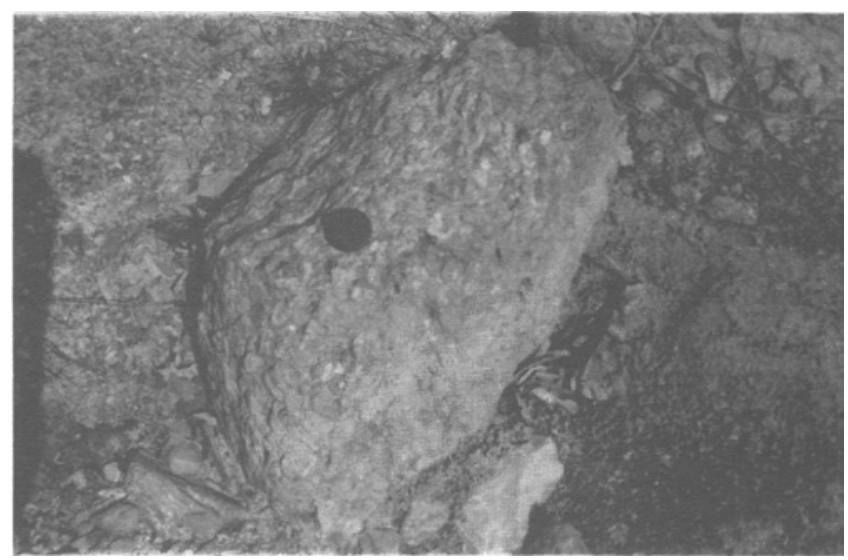

Foto 8 - Bloco de metaconglomerado similar a uma facies do conglomerado da Formação Sopa-Brumadinho do Supergrupo Espinhaço

Photo 8 - Metaconglomerate boulder similar to one facies of the SopaBrumadinho conglomerate facies of the Espinhaço Supergroup

Ainda, é importante salientar que glaciação é um processo erosional/sedimentar que atua em uma vasta região amostrando áreas fonte diversas, iniciando nas proximidades dos centros glaciais e continuando por todo o trajeto das geleiras. Portanto, além das áreas descritas anteriormente (fontes mais distais), toda a região percorrida pelas geleiras é também considerada fonte (fontes proximais). Dessa forma, as áreas fonte mais próximas são atribuídas ao pacote pelito-carbonatado e arcoseano da região cratônica recoberta pelo Grupo Bambuí.

DIAGÊNESE No caso do Grupo Santa Fé, a evolução diagenética é simplificada em decorrência da incipiente história de soterramento da bacia. Toda a pilha sedimentar paleozóica não ultrapassa $250 \mathrm{~m}$ de espessura nas áreas estudadas. O pacote cretáceo, já bastante erodido na região, contribuiu com uma coluna de cerca de 70-100 m. Com o peso de sedimentos de certa forma restrito, as reações associadas a pressões e temperaturas mais elevadas não ocorreram.
O estudo petrográfico das lâminas delgadas possibilitou o estabelecimento das linhas gerais da evolução diagenética, que podem ser visualizadas na figura 7 .

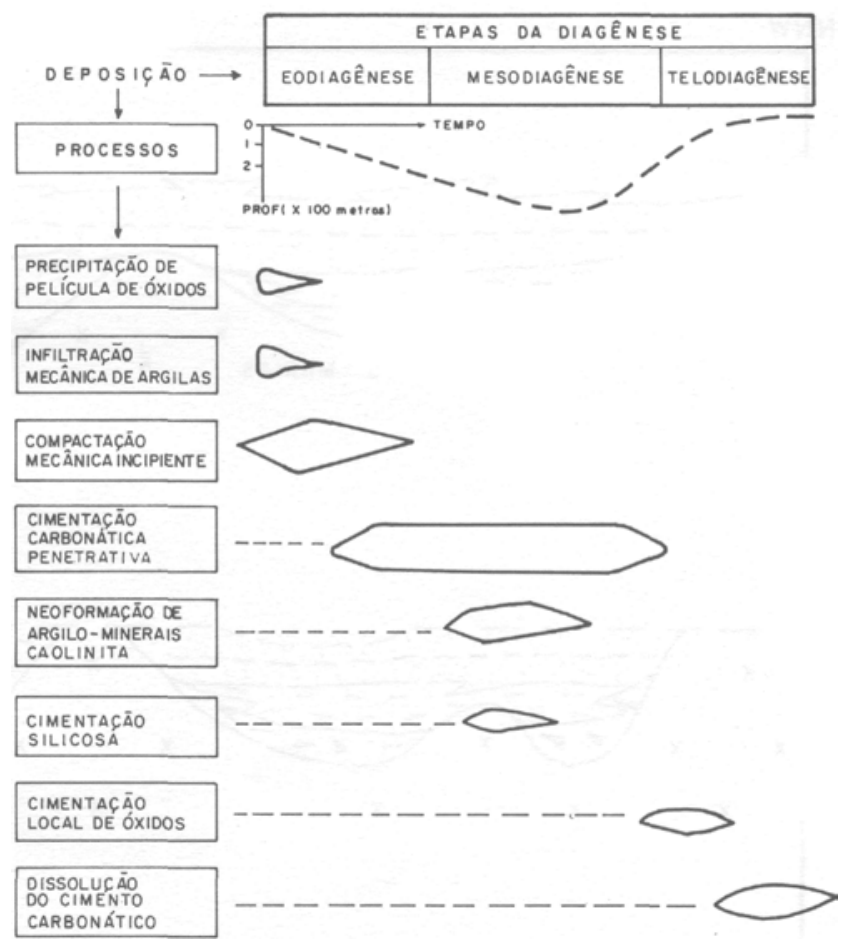

Figura 7 - Evolução diagenética no Grupo Santa Fé, nas diferentes etapas da diagênese

Figure 7 - Diagenetic evolution of the Santa Fé Group, in different diagenetic phases

PALEONTOLOGIA O posicionamento cronoestratigráfico do Grupo Santa Fé no Neopaleozóico foi possível graças à presença de sítios icnofossilíferos (icnofósseis = trace fossils = rastros fósseis). A associação fóssil é composta basicamente por dois icnogêneros, Isopodichnus e Diplichnites (Ismar de Carvalho, informação escrita). Ambos correspondem etologicamente a "traços de pastagem" (pascichnid) e "traços de locomoção" (repichnia) (Seilacher 1953, apud Fernandes et al. 1987).

O gênero Diplichinites (foto 9) é caracterizado por dois sulcos paralelos com uma crista mediana. Sua largura varia

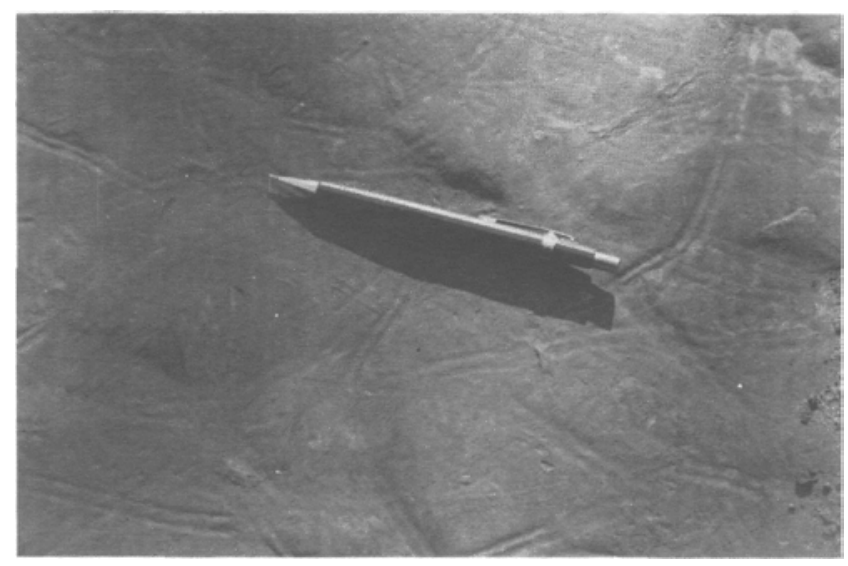

Foto 9-Icnofósseis (gênero Diplichnites j encontrados em siltitos do Membro Brejo do Arroz

Photo 9 - Ichnofossils (Diplichnites) found in siltstones of the Brejo do Arroz Membe 


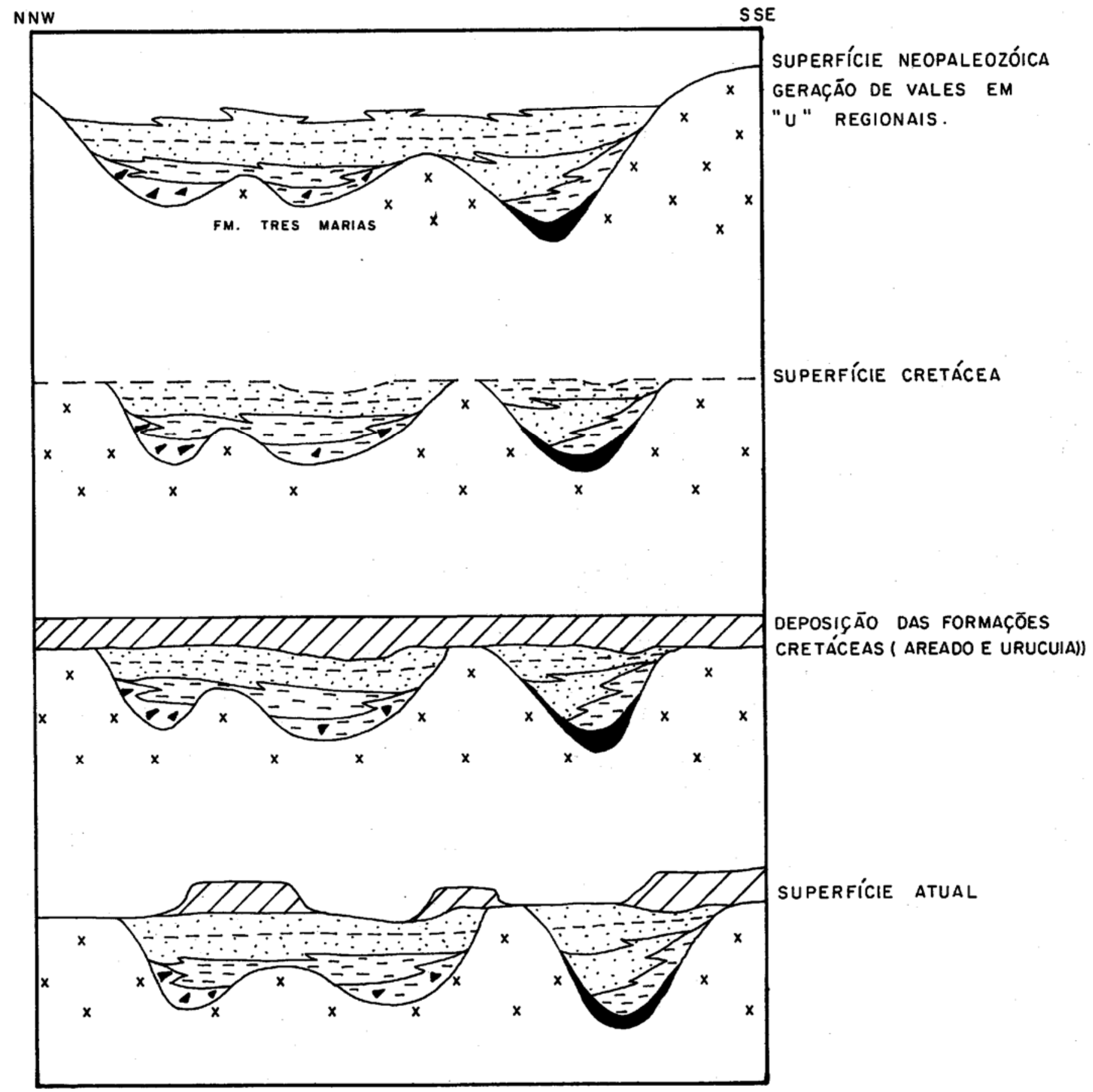

Figura 8-Evolução paleogeográfica esquemática

Figure 8 - Schematic palaeogeographic evolution

de 4 a $7 \mathrm{~mm}$ e raramente alcança $9 \mathrm{~mm}$. O arranjo interno é bastante simétrico, onde cada marca de 1 a $3 \mathrm{~mm}$ é separada por cristas de 0,5 a $2 \mathrm{~mm}$. Seu comprimento máximo, nos afloramentos, chegou a $40 \mathrm{~cm}$.

O gênero Isopodichnus mostra, como o Diplichnites, os dois sulcos paralelos simétricos com separação longitudinal, mas com finas estrias transversais. As esteias são em geral de 1 a 1,5 mm e separadas por espaços de $2 \mathrm{~mm}$. Seu máximo comprimento in situ chegou a $35 \mathrm{~cm}$. As larguras são similares às do outro icnogênero.

A forma denominada Diplichnites é a predominante. Os dois gêneros ocorrem em associações comuns, são retilíneos ou curvos e comumente se entrecortam.

As "pistas" fósseis ocorrem exclusivamente no Membro Brejo do Arroz (fácies glácio-lacustre). O desenvolvimento dos organismos deu-se em condições paleobatimétricas rã- 
sãs (lâmina d'água inferior aim, Carvalho \& Fernandes 1989). Este dado é obtido a partir da análise dos sedi mentos que preservam as marcas, que são leitos de siltitos e arenitos muito finos interacamadados aos folhemos. Estas rochas são interpretadas como produtos de depósitos interglaciais, quando os paleolagos estavam assoreados. O nível de energia do ambiente, ao contrário daquele proposto por Carvalho e Fernandes (1989), é considerado de moderada energia, já que, em alguns casos, os icnofósseis são encontrados em leitos com laminações cruzadas e marcas onduladas assimétricas.

Vários autores (apud Fernandes et al. 1987) consideram que os organismos produtores destas impressões eram crustáceos notostráceos. Savage (1971) descarta a possibilidade de os produtores terem sido insetos e miriápodes (respiram oxigênio atmosférico) ou trilobitas (ambiente marinho).

Os icnogêneros descritos são típicos de ambientes lacustrinos periglaciãis e datam a glaciação permo-carbonífera (Carbonífero Médio - Permiano Superior). Vale ressaltar que, apesar de os icnofósseis isoladamente não serem bons biodatadores, foram os únicos fósseis encontrados, e esta associação em particular é ausente nos sedimentos do Paleozóico Inferior e Médio.

PALEOGEOGRAFiA O Grupo Santa Fé foi observado em outras localidades do noroeste mineiro: São Romão, Vale do Rio Urucuia, proximidades de Unaí, proximidades de Porto Feliz (a sul de Santa Fé de Minas no vale do Rio Paracatu), além das áreas detalhadas. Este dado determina a grande regionalidade de ocorrência dos estratos glaciogênicos.

Após a deposição da seqüência, todo o pacote foi retrabaIhado sucessivamente durante o Mesozóico e posteriormente no Cenozóico. Sua preservação em áreas localizadas é condicionada pelos vales glaciais (regiões de maior potencial de preservação - maior espessura).

A análise da distribuição das fácies glaciais e sua relação com as faixas de afloramento da Formação Três Marias mostra, com clareza, que o paleo-relevo à época da glaciação era bastante arrasado. A figura 8 mostra a evolução do relevo, como segue: relevo após a chegada das frentes glaciais, entalhando a Formação Três Marias; relevo no Cretáceo, resultante da erosão desde o final do Paleozóico até o Neojurássico, gerando uma superfície muito arrasada, onde

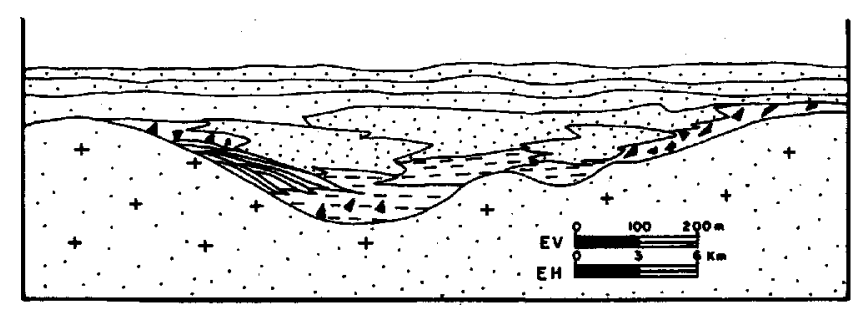

FORMACÃÓ TABULEIRO

FÁ́cIES PERIGLAL EÓLICO - LACUSTRE

FORMAGĀO FLORESTA

$\therefore$ Fá́cIes fLUVIO-GLACIAL

EAfácies glaCio- LaCUSTRE

Fá́cIes DE TURBIDITO

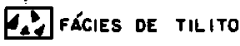

FORMAĞ̃o TRẼS MARIAS

$\because+$

Figura 9 - Geometria e interrelação das várias fácies do Grupo Santa Fé

Figure 9 - Fácies distribution and correlation in the Santa Fé Group se depositariam as formações cretáceas; passagem do Cretáceo para o Paleoceno, após a sedimentação das Formações Areado e Urucuia. A espessura do conglomerado basal da Formação Areado é controlada pelo paleo-relevo glacial; relevo atual, após erosão no Terciário e Quaternário. A Formação Urucuia é preservada em mesetas e as raízes do Grupo Santa Fé são residuais nos vales glaciais.

A situação paleogeográfica, associada aos outros argumentos descritos e discutidos anteriormente, praticamente descarta a possibilidade dos sedimentos do Grupo Santa Fé terem sido depositados em montanhas (glaciação de piemonte). Os depósitos de geleiras de altitude, apesar de gerarem os mesmos tipos petrográficos de uma glaciação continental (tilitos, arenitos, folhelhos etc.), não mostram distribuição regional tão ampla, apresentam estratos deposicionais e pavimentes polidos com mergulho moderado e geralmente são encontrados mais próximos às áreas fonte, além disso não há registros de cadeias de montanhas na região NW de Minas Gerais durante o Paleozóico.

\section{CONCLUSÕES}

- A glaciação neopaleozóica está registrada na região e seus sedimentos são englobados no Grupo Santa Fé. Na Bacia Sanfranciscana, a glaciação tem caráter exclusivamente continental;

- O embasamento regional é representado pela Formação Três Marias do Proterozóico Superior do topo do Grupo Bambuí;

- Foi possível identificar fácies de tilito, turbidito, flúvio-glacial, glácio-lacustre e eólica dentro do pacote glaciogênico;

- A Formação Tabuleiro, periglacial-eólica, representa um depósito mais amplo, que mostra expressão regional. Sua presença foi marcada em outras localidades através do tratamento digital de imagens de satélite;

- A glaciação é regional, tendo seus registros sido observados em Canabrava, Santa Fé de Minas, Unaí, Bacia do Rio Urucuia, São Romão e certamente será descrita em outras localidades da região;

- O posicionamento cronoestratigráfico da glaciação foi estabelecido a partir de estudos icnofossilíferos, indicando idade permo-carbonífera;

- Os depósitos glaciogênicos podem ser correlacionados com dezenas de outros distribuídos por todo o Continente Gondwana, constituindo o registro da mesma glaciação neopaleozóica;

- A área fonte, atribuída como geradora da seqüência glacial, é a região do Espinhaço Setentrional;

- A diagênese que afetou as rochas glaciais foi bastante simplificada, devido ao pequeno soterramento da bacia, sendo a cimentação carbonática a principal feição;

- Algumas coberturas psamo-pelito-psefíticas do extremo noroeste do estado de Minas Gerais foram erroneamente designadas por diversos autores de Formação Urucuia;

- A evolução histórica para a região pode ser sintetizada como segue:

- Término da deposição da última formação do Grupo Bambuí e tectônica de quebramento no fim do Proterozóico;

- Hiato deposicional no Paleozóico Inferior;

- Chegada das frentes glaciais e deposição do Grupo Santa Fé no Neopaleozóico, como um possível lobo glacial NE SW na Bacia Sanfranciscana;

- Hiato deposicional e retrabalhamento (erosão) do Grupo Santa Fé no Mesozóico;

- Implantação do sistema fluvial-lacustre-eólico e sedimentação da Formação Areado no Cretáceo Inferior;

- Deposição da Formação Urucuia no Cretáceo Superior por regime eólico;

- Instalação das superfícies de erosão e desenvolvimento das coberturas arenosas no Quaternário. 


\section{REFERÊNCIAS BIBLIOGRÁFICAS}

ALMEIDA, F.F.M. \& HASUI, Y. 1969. Geocronologia do Centro-Oeste brasileiro. Mineração e Metalurgia, 50(295):43-46.

AMARAL, G. \& KAWASHITA, K. 1967. Determinação da idade do Grupo Bambuí pelo método Rb-Sr. In: CONOR. BRAS. GEOL., 21. Curitiba, 1967. Anais... Curitiba, SBG. p. 214-217.

BANERJI, T. \& SEN, D.P. 1991. Permo-Carboniferous proglacial - lake sedimentation in the Sahajuri gondWana basin, India. Sedimentology, 71:47-58.

BARBOSA, 0.1965. Formacão Areado. In: CONOR. BRAS. GEOL., 19. Rio de Janeiro, 1965. Anais... Rio de Janeiro, SBG. p.

BASU, A. 1985. Reading provenance from detrital quartz. In: ZUFFA, G.G. ed. Provenance ofArenites. Cozenza, Reidel Publishing Company, p. 231-247

BOULTON, G.S. 1972. Modern artic glaciers as depositional models for former Ice Sheets. /. Geol. Soc. London, 127:361-393,

BRAUN, O.P.G. 1968. Contribuição à estratigrafia do Grupo Bambuí. In: CONOR. BRAS. GEOL., 22. Belo Horizonte, 1968. Anais... Belo Horizonte, SBG. p. 155-166.

CAMPOS, J.E.G. 1992. A Glaciação Permo-Carbonifera nas Regiões de Canabrava e Santa Fé de Minas - MG. Brasília. 104 p. (Dissertação de Mestrado, IG-UnB).

CAMPOS, J.E.G.; DARDENNE, M.A.; GONZAGA, G. M. 1992. Sobre a idade cretácea inferior dos conglomerados diamantíferos da região de Canabrava - MG. In: CONOR. BRAS. GEOL., 37. São Paulo, 1992. Boletim de Resumos Expandudos... São Paulo, SBG.

CARVALHO, I.S. \& FERNANDES, A.C.S. 1989. A icnofauna Gonduânica de Itu. In: SIMP. GEOL. SUDESTE 1. Rio de Janeiro, 1989. Boletim de Resumos... Rio de Janeiro, SBG. p. 15-16.

COSTA, M.T. \& BRANCO, J.J.R. 1961. Roteiro para a excursão Belo Horizonte - Brasilia. In: CONOR. BRAS. GEOL., 14. Belo Horizonte, 1961. Anais... Belo Horizonte, SBG. p. 1-115.

DARDENNE, M.A. 1978. Síntese sobre a estratigrafia do Grupo Bambuí no Brasil Central. In: CONOR. BRAS. GEOL., 30. Recife, 1978. Anais... Recife, SBG. v. 2. p. 597-610.

DARDENNE, M.A. 1979. A estratigrafia dos Grupos Bambuí e Macaúbas no Brasil central. Boi. Núcleo de Minas Gerais/SBG, 1:43-52.

DARDENNE, M.A.; GONZAGA, G.M.; CAMPOS, J.E.G. 1990. Descoberta de pavimentes estriados de origem glacial sobre os arcóseos da Formação Três Marias na região de Santa Fé de Minas, MG. R.E.M. 4(4):65-66.

DARDENNE, M.A. \& WALDE, D.H.G. 1979 A estratigrafia dos Grupos Bambuí e Macaúbas no Brasil central. In: SIMP. GEOL. MINAS GERAIS, 1. Diamantina, 1979. Atas... Diamantina, SBG. p. 43-53.

DREIMANIS, A. \& SCHULUCHTER, C. 1985. Field criteria for the recognition of till and tillites. Palaeogeogr. Palaeoclimatol. Palaeoecol., 51:7-14.

EDWARDS, M. 1987. Glacial environment. In: READING, H.G. ed. Sedimentary Environments and Fades. Oxford, Blackwell Scientific Publications. 615 p.

ELLIOT, R.E. 1965. A classification of subaqueous sedimentary structures based on rheological and kinematical parameters. Sedimentology, 5:193-209.

EYLES, N. \& EYLES, C.H. 1992. Glacial depositional systems. In: WALKER, R.G. \& JAMES, N.P. eds. Fades Models Response to Sea Level Change. Ontario, Geol. Assoc. Can, p. 73-100.

FERNANDES, A.C.S.; CARVALHO, I.S.; NETTO, R.G. 1987. Comentários sobre os traços fósseis do Paleolago de Itu, São Paulo. In: SIMP. REG. GEOL., 6. Rio Claro, 1987. Atas... Rio Claro, SBG. p. 297-311.

FOLK, R.L. 1956. The role of texture and composition in sandstone classification. J. Sediment. Petrol, 26:166-171.

FRANCA, A.B. 1987. Stratigraphy, Depositional Environment and Reservoir Analysis of the Itararé Group (Permo-Carboniferous),
Paraná Basin - Brazil. Cincinnati. 188 p. (Tese de Doutoramento, University of Cincinnati).

GONZAGA, G.M. \& TOMPKINS, L.A. 1987. Geologia do diamante. In: Principais Depósitos Minerais do Brasil. Brasília, DNPM-CPRM. v. $4 \mathrm{~A}$.

HARLAND, W.B.; HEROLD, K.N.; KRINLEY, D.H. 1966. The definition and identification of tills and tillites. Earth-Sd. Rev., 2:225-256.

HASUI, Y. \& ALMEIDA, F.F.M. 1970. Geocronologia do centro-oeste brasileiro. Boi. Soc. Bras. Geol., 19(1):5-26.

KATTAH, S.S. 1991. Análise Faciológica e Estratigráfica do Jurássico Superior Cretáceo Inferior na Porção Meridional da Bacia do São Francisco, Oeste do Estado de Minas Gerais. Ouro Preto. 213 p. (Dissertação de Mestrado, EM-UFOP).

LOWE, D.R. 1975. Water escape structures in coarse grained sediments. Sedimentology, 22:157-204.

MACEDO, M.H.F. \& BONHOMME, M.G. 1984. Contribuição à cronoetratigrafia das Formações Caboclo, Bebedouro e Salitre na Chapada Diamantina (BA) pelos métodos Rb-Sr e K-Ar. Rev. Bras. Geoc., 14(3): 153-163.

MARCHESE, H.G. 1974. Estromatóilios "Gymnosolidos" en ei lado oriental de Minas Gerais, Brasil. Rev. Bras. Geoc., 4(4):257-271.

MIALL, A.D. 1977. A review of the braided-river depositional environment. Earth-Sd. Rev., 13:1-62.

MILLER, J.M.G. 1989. Glacial advance and retreat sequences in a PermoCarboniferous section, central transantarctic mountains. Sedimentology, 36:419-430.

MORAES. L.C.; SEER, H.J.; FOGAÇA, A.C.C.; SGARBI, P.B.A.; SGARBI, G.N.C. 1986. Geologia das unidades cretácicas da área compreendida entre Lagoa Formosa e Carmo do Paranaíba - MG. In: CONOR. BRAS. GEOL., 34. Goiânia, 1986. Anais... Goiânia, SBG. v. 1 p. 337-344.

OLIVEIRA, M.A.M. 1967. Contribuição e Geologia da Parte Sul da Bacia do São Francisco e Areas Adjacentes. Rio de Janeiro, PETROBRÁS. p. 71-105. (Coletânea de Relatórios de Exploração 1, Ciência Técnica Petróleo, Seção Exploração de Petróleo 3).

RIMANN, E. 1917. A kimberlita no Brasil. Ann. EM-UFOP, 15:27-32.

SAVAGE, N.M. 1971. A varvite ichnocoenosis from the Dwyka Series of Natal. Lethaia, 4:217-233.

SCHOBBENHAUS, C.; CAMPOS, D.A.; DERZE, G.R.; ASMUS, H.E 1984. Geologia do Brasil. In: Texto Explicativo do Mapa Geológico do Brasil e da Área Oceânica Incluindo Depósitos Minerais. Brasília, MME-DNPM. 501 p.

SCHOLL, W.H. 1973. Sedimentologie und Geochemie der BambuiGruppe am SE - Rand dês São Francisco - Beckens, Minas Gerais, Brasilien. Heidelberg. 301 p. (Tese Doutoramento, Universitat Heidelberg).

SEILACHER, A. 1953. Studien zur Palichnologie. I. Uber Die Methoden Der Palichnologie. N. Jb. Geol. Palãont. Abh., 96:412-452.

SGARBI, G.N.C. 1989. Geologia da Formação Areado. Cretáceo Inferior a Médio da Bacia Sanfranciscana, Oeste do Estado de Minas Gerais. Rio de Janeiro. 224 p. (Dissertação de Mestrado, IG-UFRJ).

TOMPKINS, L.A. \& GONZAGA, G.M. 1989. Diamond in Brazil and a proposed model for the origin and distribution of diamonds in the Coromandel region, Minas Gerais, Brazil. Econ. Geol., 84:591-602.

WALKER, R.G. 1979. Turbidites and associated coarse clastic deposits. In: WALKER, R.G. ed. Fades Models. Ontario, Geoscience Canada. 211 p. (Reprint Series 1).

MANUSCRITO A761

Recebido em 11 de maio de 1993 Revisão do Autor em 29 de novembro de 1994 Revisão aceita em 18 de abril de 1995 